\title{
Comparison study between two types of nozzles for a turbocharger balancing machine using ANSYS software
}

\author{
Sigismund Becze ${ }^{1, *}$, and Gheorghe Ioan Vuscan ${ }^{1}$ \\ ${ }^{1}$ Technical University of Cluj-Napoca, Memorandumului 28, 400114 Cluj-Napoca, Romania
}

\begin{abstract}
Turbocharger balancing machines require a specific tooling for spinning the center housing rotating assembly, in order to balance it dynamically. The tooling requires a nozzle to guide the air to the blades of the turbine wheel in order to spin it. Depending on the type of nozzle chosen, the maximum rotational speed achieved and the acceleration curve can be different. In today's market there is an increasing demand for a higher turbocharger speed, generally driven by the demand for engine downsizing and for a higher performance. Due to that, turbochargers need to be better balanced, thus requiring a wider measurement range of the unbalanced in order to see how the part performs in all its working range. Consequently, the nozzles used by turbocharger balancing machines need to be verified at a higher speed limit.
\end{abstract}

\section{Introduction}

Today's turbocharger industry, characterized by an increasing operational speed, one of the challenges is to deliver better balanced components. Thus the measurement instruments need to have a higher sensitivity and a wider speed range. In order to achieve that, companies strive to use high performance balancing machines which deliver better core tool vibration insulation, a higher speed and more accurate measurements and balancing [1, 2 ]. Besides all the other challenges, and despite the fact that there are better components available on today's developing market, the maximum rotational speed of the turbocharger placed on the balancing machine has the same unchanged constrains: $600 \mathrm{kPa}$, cold air. This is due to safety regulations and to industry standard compressors [3, 4].

In this context, the nozzles are playing an important role in ensuring that the balancing machine delivers the maximum performance when spinning the shaft. For the purpose of this paper we simulated the flow using 2 different nozzles at $600 \mathrm{kPa}$ cold air pressure.

The main difficulty was to achieve high air speed and flow when the pressure was limited to $600 \mathrm{kPa}$ by safety and industry standard regulations. What was observed using nozzles for different types of turbines was that, besides the air speed, the air flow had a major impact in accelerating various sized turbine wheels. The conclusion was that it was necessary to analyze and optimize the air flow and speed in turbocharger balancing machines.

\footnotetext{
*Corresponding author: bsigismund@gmail.com
} 
In the following pages we analyzed a chambered nozzle similar to those which are widely used in turbocharger balancing machines. Generally, they have various sizes and different outlet holes. We compared it to a prototype devised by the authors based on observations and various optimizations.

\section{Abbreviations}

CAD - computer aided design

FEA - finite element analysis

CFD - computation fluid dynamics

CHRA - center housing rotating assembly

ID - inner diameter

OD - outside diameter

\section{Simulation conditions}

The Catia V5 software was used to design and prepare the 3D models. The meshing and the analysis were performed using Ansys Fluent. Nozzle 1 (fig. 1a) is similar to the industry standard. The model was prepared as shown in fig. $1 \mathrm{~b}$.

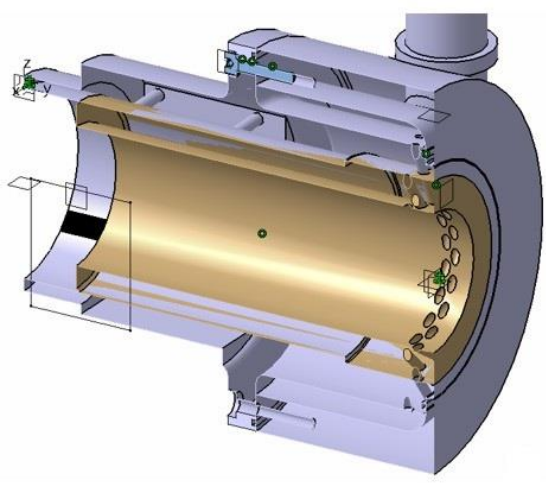

a)

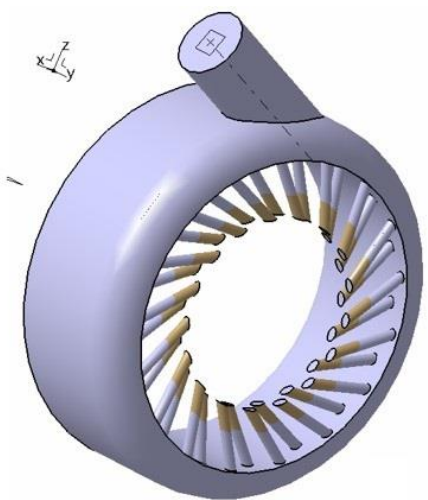

b)

Fig. 1. a) The 3D model of the standard nozzle (nozzle 1). b) FEA prepared model.

Nozzle 1 used an air inlet, an expansion chamber and multiple directed holes as a circular nozzle system, as shown in fig. 1.

The new version we propose (nozzle 2) used an inlet of the same type $\&$ size with a guiding shape on a conical helix with a single outlet directing the flow in a tangential direction (fig. 2).

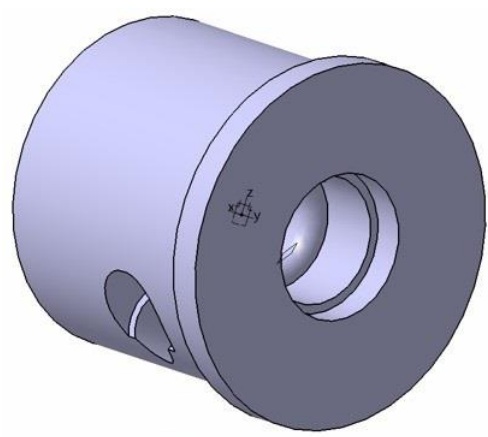

a)

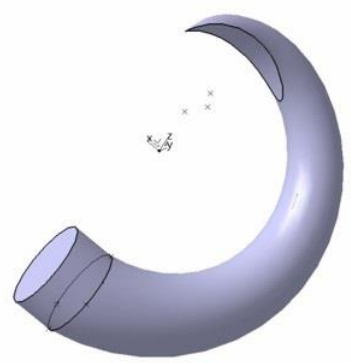

b)

Fig. 2 a) New nozzle (nozzle 2) 3D b) New nozzle FEA ready model 
For meshing nozzle 1, we used tetrahedron elements, with a fine mesh size. We could not use brick-type elements due to the geometrical complexity of the piece (fig. 3).

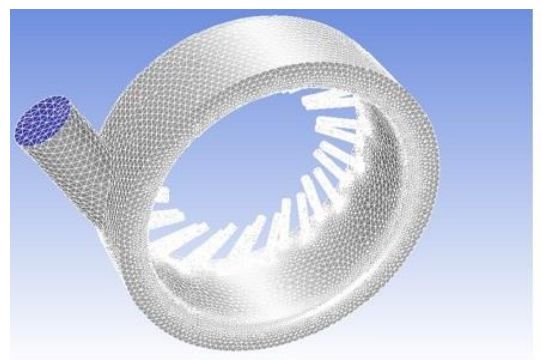

a)

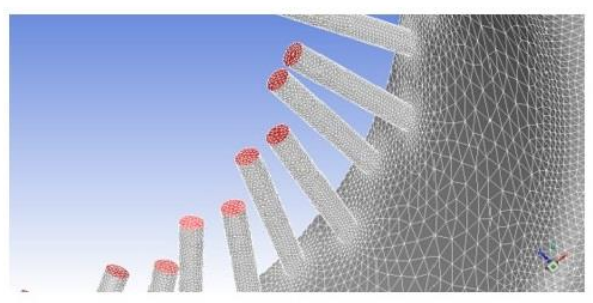

b)

Fig. 3 Meshing of nozzle 1

For nozzle 2 we used brick elements, with a mapped meshing option (see fig. 4).

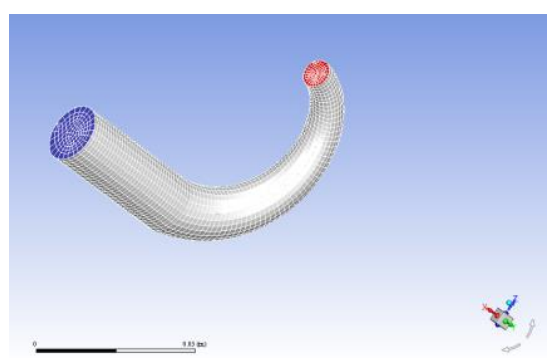

Fig. 4 Meshing of the nozzle 2

\section{Calculation and data evaluation}

The calculations were based on the premise that air pressure is at $600 \mathrm{kPa}$ constantly. Our other assumptions were the following:

- $\quad$ inlet pressure $=600 \mathrm{kPa}$

- $\quad$ outlet pressure $=101,3 \mathrm{kPa}$

- $\mu$ - air dynamic viscosity

- $\quad \mathrm{P} 1=600 \mathrm{kPa}$

- $\quad \mathrm{P} 2=101,3 \mathrm{kPa}$

- $\rho=1.1455 \mathrm{~kg} / \mathrm{m}^{\wedge} 3$ at $35^{\circ} \mathrm{C}$

- $\mu=1.895 \times 10-5 \mathrm{~kg} / \mathrm{m}-\mathrm{s}$ [5]

- a 6" hose of $1 \mathrm{~m}$ was used for inlet, with $42 \mathrm{~mm}$ ID.

- Inlet diameter $\mathrm{D}=19 \mathrm{~mm}$ for both variants.

Using Poiseuille's equation [6] for compressible fluids, the volumetric flow rate was calculated using formula 1 [7]. The obtained result for Q was $0.865 \mathrm{~L} / \mathrm{s}$

where:

$$
Q=\frac{d V}{d T}=\mathrm{v} \pi \mathrm{R}^{2}=\left(\frac{\pi R^{4}}{16 \mu L}\right)\left(\frac{P i^{2}-P o^{2}}{P o}\right)
$$

$\mathrm{Q}$ - is the volumetric flow rate

$\mathrm{Pi}$ - is the inlet pressure

Po - is the outlet pressure

$\mathrm{L}$ - is the length of the tube

$\mu \mu$ \{displaystyle $\backslash \mathrm{mu}\}$ - is the viscosity 
$\mathrm{R}$ - is the radius of the pipe

$\mathrm{V}$ - is the volume of the fluid at outlet pressure

$v$ - is the velocity of the fluid at outlet pressure

The hose length was considered to be of $1 \mathrm{~m}$, with a bore of 2", an outside diameter of $60.3 \mathrm{~mm}$ and an internal diameter of $52 \mathrm{~mm}$.

Inlet area for both nozzles: $\mathrm{A} 1=\pi * 9.52=283.528 \mathrm{~mm}^{2}$.

For nozzle 1:

Inlet ID: $19 \mathrm{~mm}$

Outlet ID: $4.5 \mathrm{~mm}$

Outlet area for 1 nozzle at type $1: \mathrm{A} 2=\pi * 4.52=15.904 \mathrm{~mm} 2$

Using $\mathrm{Q}=\mathrm{Av}, \mathrm{v} 1=\mathrm{Q} / \mathrm{A} 1=0.865 / 0.0002835280=3.0508 \mathrm{~m} / \mathrm{s}$

The resulting outlet velocity is $\mathrm{v} 2=\left(\mathrm{A} 1 *_{\mathrm{v}} 1\right) / \mathrm{A} 2=15.420 \mathrm{~m} / \mathrm{s}$

For nozzle 2:

Inlet ID: $19 \mathrm{~mm}$

Outlet ID: $7 \mathrm{~mm}$

Outlet area: $\mathrm{A} 2=\pi * 3.52=38.484 \mathrm{~mm} 2$

$\mathrm{v} 2=(\mathrm{A} 1 * \mathrm{v} 1) / \mathrm{A} 2=22.4762 \mathrm{~m} / \mathrm{s}$

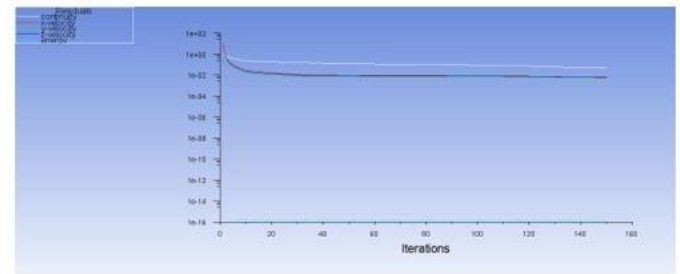

a)

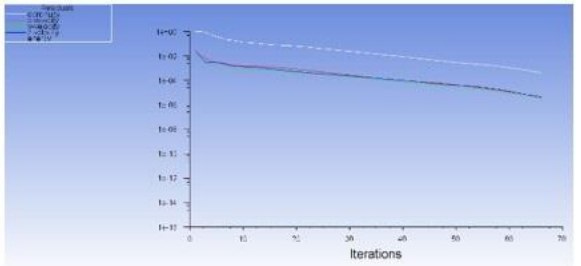

b)

Fig. 5 Velocity and energy a) Nozzle 1; b) nozzle 2

The top velocity registered at some of the outlets of the standard nozzle 1 was significantly higher than the one registered in the case of the nozzle 2 (fig. 5 a). However, the measurements showed that the average velocity registered at the outlets of standard nozzle 1 was much lower, as most of the velocity was lost in the expansion chamber. Thus, only a few of the outlet holes of nozzle 1 delivered a high-speed airflow (fig. 6a), while the others delivered a lower airflow. The fact that the airflows were unequal limited the energy that could be transmitted to the turbine wheel.

Nozzle 2 showed a significant energy value at the outlet. This means that a significant velocity was concentrated at the outlet area, as shown in fig. $6 \mathrm{~b}$ ).

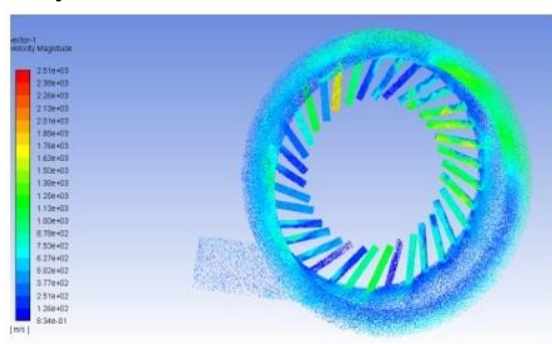

a)

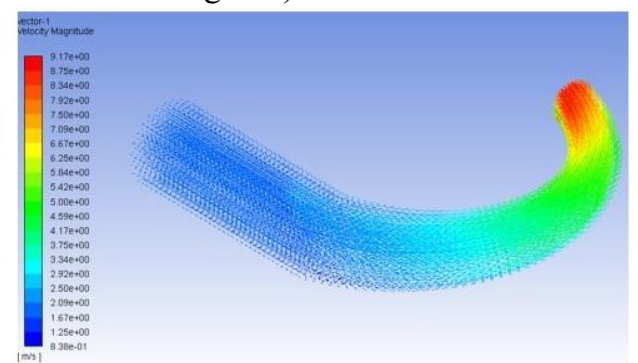

b)

Fig. 6 Velocity a) Nozzle 1; b) nozzle 2 
In other words, nozzle 1 lost velocity in the air chamber and the design did not manage to deliver an equal velocity at the small outlet holes, thus not managing to deliver an equal air speed. Nozzle 2 showed a smaller velocity loss, delivering maximum velocity at the end of the nozzle, where it was needed.

Static pressure distribution was not uniform in the case of nozzle 1 (fig. 7a), showing a more equal distribution in the case of nozzle 2 (fig. $7 \mathrm{~b}$ ).

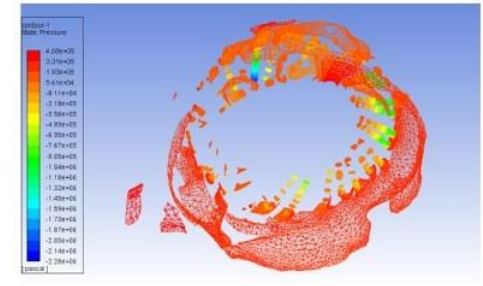

a)

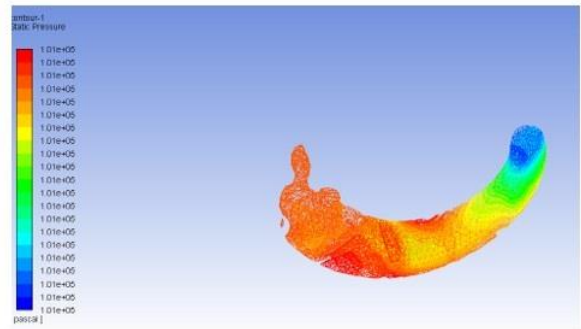

b)

Fig. 7 Contour pressure static a) nozzle 1; b) nozzle 2

The dynamic pressure in the case of nozzle 1 showed turbulences (fig. 8a), while nozzle 2 showed a more laminar flow (fig. 8b).

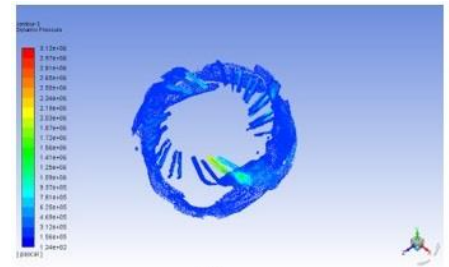

a)

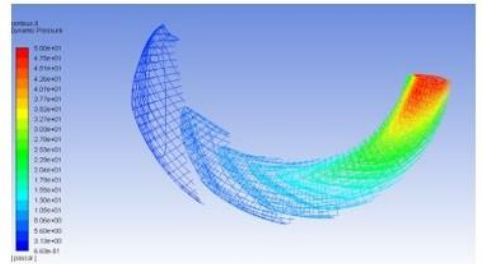

b)

Fig. 8 Contour pressure dynamics a) nozzle 1; b) nozzle 2

The dynamic pressure showed an unequal distribution in the case of nozzle 1 and a better distribution in the case of nozzle 2 .

The particle path showed clearly that nozzle 1 had a higher risk of turbulences, leading to a loss of energy (fig. 9a), while nozzle 2 had a lower risk of turbulence flow, directing the energy directly to the outlet.

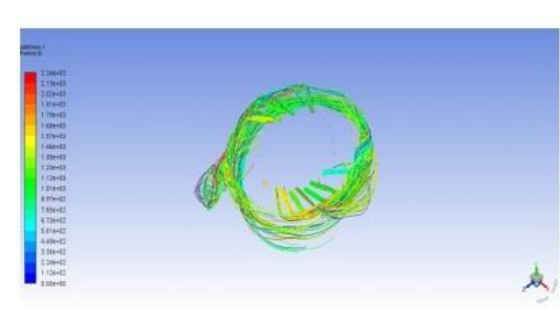

a)

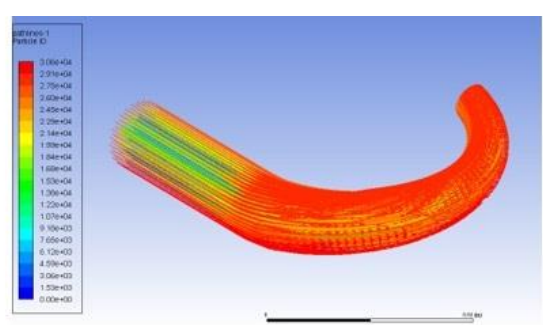

b)

Fig. 9 Particle path a) nozzle 1; b) nozzle 2 


\section{Conclusions}

The nozzle we propose, nozzle 2, outperformed the standard nozzle 1 in terms of energy transfer to the outlet, having a lower probability of turbulence, even if the top velocity was higher at some outlets of nozzle 1 .

In the case of nozzle 1, the velocity, energy and pressure were lost mainly in the air expansion chamber, as the outlets were not orientated in the direction of the flow, thus changing the airflow and creating turbulences (fig. 9a). Nozzle 2, even if it delivered a significantly lower top velocity, concentrated air speed at the outlet, delivering the highest energy where needed with a laminar flow (fig. 8b), thus outperforming nozzle 1 .

\section{References}

1 J. Chen Wen, E.J. Gunter, Introduction to dynamics of Rotor-Bearing Systems, (Trafford Publishing, Canada, 2007)

2 E.J. Gunter, J. Chen Wen, Dynamic stability and whirl motion of large diesel engine turbochargers in floating bush and multi-lobed bearings (Vibration Institute 34th Annual Meeting, June 22-26, 2010 Oak Brook, Illinois)

3 E.J. Gunter, R.R. Humphris, H. Springer, AMD Vol. 55, (1983).

4 E.J. Gunter, 7th IFToMM-Conference on Rotor Dynamics, Vienna, Austria, (2006).

$5 \quad * * *, \quad$ https://www.engineersedge.com/physics/viscosity_of_air_dynamic_and_ kinematic_14483.htm, accessed on 14.05.2019.

6 ***, https://www.parker.com/Literature/Literature\%20Files/pneumatic/serv/ TEC15.pdf, accessed on 14.05.2019.

7 ***, https://ipfs.io/ipfs/QmXoypizjW3WknFiJnKLwHCnL72vedxjQkDDP1m XWo6 uco/wiki/Hagen-Poiseuille_equation.html, accessed on 14.05.2019. 